\title{
Gender equality in marine sciences in Kiel, Germany: how project-funded measures can urge institutions to act
}

\author{
Ruth Kamm ${ }^{1}$, Christiane K. Schelten ${ }^{2}$, and Gesche Braker ${ }^{3}$ \\ ${ }^{1}$ Central Office for Gender Equality, Diversity and Family, Kiel University, Christian-Albrechts-Platz 4, 24118 Kiel, Germany \\ ${ }^{2}$ GEOMAR Helmholtz Centre for Ocean Research Kiel, Düsternbrooker Weg 20, 24105 Kiel, Germany \\ ${ }^{3}$ Postdoc Center, Kiel University, 24118 Kiel, Germany
}

Correspondence: Ruth Kamm (rkamm@gb.uni-kiel.de)

Received: 5 December 2019 - Revised: 26 May 2020 - Accepted: 19 June 2020 - Published: 22 July 2020

\begin{abstract}
In Kiel, in the north of Germany, marine research is rooted in a lively research community hosted mainly at Kiel University and the GEOMAR Helmholtz Centre. While the ratio of women and men is more or less balanced on all qualification levels with mainly nonpermanent junior positions, women are generally underrepresented in leading research positions. The problem of gender imbalance and inequality has been well-known for a long time. Especially in the last decade, however, manifold efforts were initiated to improve gender equality on a political and institutional level as well as within the research community itself. In our article we focus on the gender equality activities of the two large externally funded marine sciences research alliances: the Cluster of Excellence "The Future Ocean" and the Collaborative Research Centre 754 "Climate-Biogeochemistry Interactions in the Tropical Ocean". For about a decade they offered both financial provisions and a structural framework to tackle the problem of women's underrepresentation in science and came up with innovative measures.

In the following case study, we not only introduce the situation of women in marine sciences in Kiel and the structural arrangement to improve gender equality in general, but we also discuss three specific measures developed within the two collaborative research projects in detail: (i) the mentoring program via:mento_ocean for female postdocs, (ii) hiring policies integrating a gender quota for recruiting postdoctoral researchers and (iii) a code of conduct. Based on these bestpractice examples we can show that progress towards gender equality has been made despite some obstacles faced when implementing the measures. This was especially the case for attracting female researchers to work in Kiel marine sciences and bringing the relevance of the topic to the surface of de-
\end{abstract}

bates within the community. Looking at gender equality activities from a managerial point of view, we conclude from the situation in Kiel, where external funding for both research alliances ended in 2019, that even time-bound activities can initiate change. Initiatives developed by the marine sciences community were taken up by other research groups and inspired new activities at the level of the institutions involved.

\section{Why support gender equality in marine sciences}

Academic disciplines in the field of science, technology, engineering and mathematics (STEM) have been traditionally male dominated and still are. In Europe, participation levels of women are lower than those of men at all stages of the academic career path and are especially decreasing in academic leadership positions (She Figures, Fig. 6.2, p. 117). This general trend is also true for marine sciences as was shown for the US (Orcutt and Cetinić, 2014) and for Europe, for example, by mapping eight marine sciences institutions in the Baltic Sea region by the EU-funded project Baltic Gender (Baltic Gender, 2020; 2019; see Sect. 5).

In the last decade, the underrepresentation of women in STEM in general and in geosciences and marine sciences in particular has increasingly been perceived as problematic. Meanwhile, this is considered an obstacle for women researchers' career prospections that has to be addressed and tackled not only by women themselves. Awareness has developed that special attention is needed and that action also has to be taken at political and institutional levels. The European Union, for example, addressed gender equality within the "Support to research organizations to implement gender 
equality plans" action within Horizon 2020, wherein several projects with a focus on gender equality in STEM disciplines were funded (GenderSmart, 2020). By now, sessions on the support and promotion of equality are held at the European Geosciences Union (EGU) General Assembly on an annual basis, and the EGU Working Group on Equality, Diversity and Inclusion was founded in 2018.

In this article, we describe marine sciences in Kiel, Germany, as a case study. Local activities to promote gender equality in marine sciences are presented. We show that local efforts are not isolated initiatives. Increased efforts to improve gender equality within research institutions are closely linked not only to legal obligations on the national and federal level as well as the changing regulations of funding agencies, but also to an increased awareness of the research community itself.

\section{Women in marine research institutions in Kiel}

Kiel is home to two well-known German institutions in the field of marine research: GEOMAR Helmholtz Centre for Ocean Research Kiel and Kiel University. GEOMAR is a nonuniversity research institution belonging to the Helmholtz Association with around 500 scientists (GEOMAR, 2020a). The research focus on classical marine disciplines (geology, meteorology, physical and biological oceanography) explains the gender imbalance of only $14 \%$ women in Grade A and Grade B positions, which are equivalent to senior professorship positions, in 2014. Furthermore, only $17 \%$ of permanent scientist positions below the professorship level were filled by women (GEOMAR, 2015). In 2019 the gender ratio in leading positions was $25 \%$ women and $75 \%$ men, although the overall share of women in academic positions at GEOMAR was higher than $40 \%$ (Baltic Gender, 2019). This shows that despite enhanced efforts to recruit highly qualified women in leadership positions, the positive developments towards gender balance at the levels below did not equally affect leadership and decision-making levels.

Kiel University is Germany's northernmost comprehensive state university. Marine research is anchored in a wide range of disciplines bundled in the Centre for Interdisciplinary Marine Science, Kiel Marine Science (KMS). KMS is one of the university's four priority research areas and brings together more than 40 research groups from seven of the university's eight faculties (KMS, 2020). In May 2020 KMS had 50 members with a female share of $28 \%$ (KMS, 2020). Due to the interdisciplinary approach to marine sciences, numbers on women in marine sciences cannot be presented separately. Most researchers with a marine focus are affiliated with the Faculty of Mathematics and Natural Sciences, wherein the share of women in Grade A and Grade B positions also lies slightly below $25 \%$. This is similar to the numbers considering the whole university (Baltic Gender,
2019). The situation of permanently employed research staff is comparable to GEOMAR. In 2014 only $19 \%$ of permanent scientist positions below the professorship level at Kiel University's Faculty of Mathematics and Natural Sciences were filled by women. This proportion increased to $26 \%$ in 2019 , but it was significantly below the university-wide share of $28 \%$ in 2014 and $41 \%$ in 2020 (Kiel University, 2020 ${ }^{1}$ ).

The proximity of GEOMAR and Kiel University is also reflected in joint efforts for marine research based in Kiel. For example, all GEOMAR professors teach in the university's study programs because they are jointly appointed by both institutions. Guidelines on appointing have been in force for over a decade now. They entail regulations with relevance to gender equality such as the active recruitment of female scientists, clear rules for avoiding bias, and allowing applicants to be assessed without prejudice or considering family leaves of absence when evaluating scientific achievements. All in all, these guidelines result in highly transparent procedures. Currently the overall appointment of women to leading positions in marine sciences exceeds their share of positions that are already filled. Between 2012 and $201950 \%$ of the appointments to Grade A and Grade B positions were women, and in the last 5 years the number of women (five) exceeded the number of men (two) starting a professorship in marine sciences in Kiel (Baltic Gender, 2019; internal statistics on the proportion of women by Kiel University). For the first time a woman was appointed to the position of the scientific director of GEOMAR from October 2020 onwards (GEOMAR, 2020b).

The cooperation of GEOMAR and Kiel University is particularly grounded in joint research endeavors with a marine focus. From 2006 onwards, the Kiel-based marine research community was dedicated to integrative ocean research under the framework of the Cluster of Excellence "The Future Ocean". The focus of "The Future Ocean" is the better understanding of past, present and future changes in the ocean system in order to develop scientifically based global and regional options for improved sustainable ocean governance and protection. In total, more than 250 scientists from Kiel University, GEOMAR and their Kiel-based partner institutions - the Institute for the World Economy (IfW) and the Muthesius Academy of Fine Arts - combine their expertise not only in ocean science but also in geography, mathematics, nanoscience, life science, applied mathematics, informatics and engineering, environmental economics, international law, political science, theology, philosophy and environmental ethics. For 13 years, the Cluster of Excellence "The Future Ocean" was funded within the Excellence Initiative by the German federal and state governments. This

\footnotetext{
${ }^{1}$ The Central Office for Gender Equality, Diversity and Family updates its statistics on the proportion of women at Kiel University annually so that only the current figures are publicly available. Several figures on the gender ratio mentioned throughout the text are based on internal, unpublished statistical material.
} 
included the necessity to build up a governance structure for the cluster, which ties together marine sciences at GEOMAR and Kiel University. This overarching structure opened up chances for joint activities to support gender equality, too, and to exert at least an indirect influence on gender politics at both institutions (Future Ocean, 2020). Although also starting with a low fraction of women in professorship and postdoc positions, the gender ratio in the Cluster of Excellence changed positively during the project's funding time and reached a roughly balanced situation on all scientific levels towards the end. At the end of 2019, the funding of "The Future Ocean" within the funding scheme of Clusters of Excellence ended and the structured cluster was transferred into the "Future Ocean Network". This network is a new platform for both the communication of activities around common topics and the development of new joint integrative marine research initiatives in Kiel.

Between 2008 and 2019, the Collaborative Research Centre "Climate-Biogeochemistry Interactions in the Tropical Ocean" (SFB 754) addressed the threat of ocean deoxygenation, its possible impact on tropical oxygen minimum zones and implications for the global climate-biogeochemistry system. Collaborative Research Centres (CRCs) are funded by the German Research Foundation (DFG). The SFB 754 was jointly conducted by scientists of Kiel University and GEOMAR. Therefore, when developing its equalopportunity concept (SFB 754, 2020), the SFB 754 was able to refer to the existing offers and structures to support gender equality at both institutions. As the DFG requirements for gender equality concepts for CRCs changed during the entire SFB 754 duration (see Sect. 4), the aims the SFB 754 set for its funding periods also became more specific. Since 2012, the SFB 754 has focused on financing at least $50 \%$ female doctoral and postdoctoral researchers - an ambitious aim considering that in marine sciences the female share is generally below $50 \%$. However, despite some fluctuations, particularly towards the end of the various project funding periods, the SFB 754 succeeded in reaching this target. Due to the national and international gender gap, increasing the female share on a higher level (principal investigator) was much more difficult. The SFB 754 ran out in December 2019 after the maximum funding period of 12 years. By then, the percentage of female principal investigators had increased from $9 \%$ to $19 \%$.

Both "The Future Ocean" and the SFB 754 used their scope of action and substantial financial commitment to address the problem of female underrepresentation and committed themselves to supporting gender equality beyond the institutional minimum standards given by GEOMAR and Kiel University.

\section{Support structures to improve equal opportunities at GEOMAR and Kiel University}

Equal-opportunity work at GEOMAR and Kiel University is based on different legal obligations. Being a member of the Helmholtz Association, GEOMAR follows federal law with respect to gender equality (the Federal Equality Law). Kiel University is a state university. The legal basis of its gender equality efforts is composed of the Higher Education Act and the Gender Equality Act of the Federal State Schleswig-Holstein. Both GEOMAR and Kiel University, however, have the legal obligation to draw up a gender equality plan defining goals and measures to achieve them. The gender equality plan is adopted by the GEOMAR directorate and the university board, respectively.

At GEOMAR, two main units primarily focus on supporting equal opportunities and promoting women in science. By law, all female employees elect an equal-opportunity officer (EOO) and her deputy every 4 years. The main objective of their work is to abolish the structural disadvantages of women by specifically promoting them during recruitment, but also while working at GEOMAR. The current team is especially committed to fair hiring processes, the improvement of work-life balance and family-friendly working conditions, the career advancement of women, and the enhancement of the institutional culture (GEOMAR, 2020c). In addition to the EOOs, who represent all female staff members at GEOMAR, women in leading positions founded the Women's Executive Board (WEB) in 2013. GEOMAR is the only Helmholtz Centre that has installed such a board. The WEB's mission is also to support a modern equal-opportunity-oriented working culture in science, which means the equal participation of female and male scientists at all levels of the institution. Therefore, they encourage and support qualified and motivated women to stay in science (GEOMAR WEB, 2020). GEOMAR assigns both the EOOs and the WEB annual budgets to implement activities and measures corresponding to their targets. To mention a few examples, the EOOs organize workshops and an annual plenary assembly of all women at GEOMAR, and they award reentry positions for women after a family leave of absence through the Inge-Lehmann-Fonds. This is based on a flexible equal-opportunity budget set aside by the GEOMAR directorate and distributed by the EOOs twice a year through an open call to GEOMAR employees in need. Next to trainings and workshops for female scientists, the WEB's major activity is the GEOMAR Marie Tharp Lecture Series for Ocean Research: internationally renowned female marine scientists give a public lecture. Additionally, they attend a get-together especially for female GEOMAR PhD candidates and postdocs to discuss personal experiences along the academic career path. As role models, they can motivate female researchers in junior positions to pursue their academic careers. Both the EOOs and WEB representatives participate in several GEOMAR boards and committees, and the EOOs 
also have the legal obligation to participate in personnel selection procedures.

In general, activities to realize equal opportunities at Kiel University aim at all university staff and students. By law, Kiel University has a central equal-opportunity commissioner who represents all female members of the university and advises and supports the university board in putting gender equality in science into action as well as reducing discrimination against women at the university. The equalopportunity commissioner is involved in all personnel selection processes, including the appointment procedures for professorship positions, and participates in major decisionmaking processes. For example, she has permanent guest status at the university board meetings, and she is a member of the senate, the highest decision-making body of the university. The equal-opportunity commissioner is elected into a full-time position. As specified by law, she has three deputies and equal-opportunity commissioners in each faculty to support her. They all have nonexecutive positions. The human and financial resources of the university's Central Office for Gender Equality, Diversity and Family are not statutory but granted by the university itself. The office team supports day-to-day work and executes specific projects such as mentoring programs for female postdocs and family services. Through the annual budget, smaller projects, e.g., workshops or the conference participation of female scientists, can be financially supported on demand. These central measures are complemented by activities on the faculty level (Kiel University, 2020). All activities are designed to address general multidisciplinary needs. Hence, all female marine scientists working at Kiel University can take advantage of these offers to promote gender equality and women in science.

To sum it up: the local marine sciences community in Kiel is mainly based at two organizationally independent institutions, which are subject to different legal bases. While professors and doctoral candidates registered with a faculty at Kiel University, who work at GEOMAR, are automatically members of the university, this is not the case for postdocs having a contract with GEOMAR. Members of Kiel University without a contract with GEOMAR, however, are not formally affiliated with GEOMAR. Despite joint scientific networks, notable groups are therefore excluded from participation in offers by the other institution. This also includes offers to support gender equality. This is one reason why the marine sciences community in Kiel established its own transinstitutional tailor-made gender equality policies and measures. They were integrated into the already described joint marine research projects of GEOMAR and Kiel University, SFB 754 and "The Future Ocean". Major reference points for these activities were the expectations and obligations to improve gender equality required within the corresponding funding schemes. They are introduced in detail in the following section.

\section{Funding structures and joint initiatives to support gender equality in marine sciences in Kiel}

Although having a clear scientific focus on marine research questions, "The Future Ocean" and the SFB 754 are funded within program lines emphasizing the responsibility of the projects' research community to promote equal opportunities for women and men. The DFG expects CRCs to accompany scientific programs with a strategy to support gender equality.

Action is expected in three areas. First, the number of female researchers in leading positions should be increased and a sufficient number of women as principal investigators should be involved. Furthermore, the DFG explicitly asks CRCs to set target quotas for hiring female PhD students and postdocs from the start of the CRC that should be readjusted for the subsequent funding phases. Efforts to attract women to the CRC are critically assessed during the review process and are an important funding decision criterion. In the case that posts are not allocated equally to women and men, CRCs have to explain why and measures to change this have to be shown. Second, next to purely scientific aspects the career advancement of female doctoral candidates and postdocs should be supported. Typical fields are strategic career planning, self-presentation or network building. Generally, encouragement to pursue an academic career is high on the agenda. Thus, the financing of supportive staff during parental leave as well as during phases of caretaking obligations for elder relatives is important. Third, working conditions should be improved for all CRC members with family obligations. This addresses flexible working arrangements, childcare support during project-related meetings and events, and family-friendly meeting hours. To implement their strategy and to develop matching measures in these three lines of action, CRCs can request up to EUR 30000 annually for equal-opportunity activities in their proposals (DFG, 2011: 1). The SFB 754 was able to access this money in its second and third funding phase, which was the basis for some of the major activities conducted in the following years.

Such detailed specifications with regard to gender equality activities are not requested by Clusters of Excellence and funding is not earmarked. There is no specific funding module for gender measures provided, but Clusters of Excellence have a high amount of flexibility to dedicate funds for research support to activities promoting gender equality. In the funding criteria, however, the support of equal opportunity was explicitly mentioned (DFG, 2016) and expectations were high. The international review panels involved in the funding decisions recognized the low level of female principal investigators planned for the Excellence Initiative's first funding phase (2006-2012). They lacked the development of adequate strategies to counter these and other gender imbalances. This critique was taken seriously by the DFG and the German Council of Science and Humanities (Wissenschaftsrat), which executed the program (Zuber, 2010). 
Consequently, gender equality came into focus as an evaluation criterion for applications of the subsequent funding phases. These requirements primarily address structural aspects of gender imbalances. In contrast to the EU level, gender in research content is not yet critical for evaluating research proposals in Germany, although the DFG, for example, mentions the gender dimension in research in its Guidelines for Safeguarding Good Research Practice (DFG, 2019).

Both marine research alliances in Kiel showed an honest interest in understanding the reasons for the existing gender disparity. "The Future Ocean", for example, participated in an in-depth case study on gender equality in the Excellence Initiative. The SFB 754 developed a concept for extensive external monitoring of its experience with gender and diversity aspects, which unfortunately could not be realized due to restrictions on the possibilities to spend funds.

Initially, the gender equality activities of "The Future Ocean" and the SFB 754 addressed each research community separately. At the beginning of the second funding phase of both projects, however, a jointly financed coordination position for gender activities was created, and a coordinator for gender measures was hired in November 2012 with $20 \mathrm{~h}$ of working time per week. It was a strategic decision to locate this position at the Central Office for Gender Equality, Diversity and Family at Kiel University as the lead partner in equal-opportunity work. The coordinator was a full member of the Central Office's team but also in close exchange with the coordination office of "The Future Ocean" and with the scientific coordinator of the SFB 754. This organizational structure was chosen to profit from existing structures and initiatives in the central multidisciplinary setting of Kiel University and at the same time create the opportunity to come up with adaptations for the entire marine sciences community spread over the university and GEOMAR. With regard to the German university landscape, this trans-institutional position with a focus on one thematic area was unique. Similar positions at other universities do not have a thematic focus (Netzwerk GenderConsulting, 2020). The main tasks of the coordinator for gender measures was to establish a mentoring program for female postdocs tailored to the needs of the marine sciences community and to organize and support further gender activities within both research communities. All measures developed for both research alliances followed a bifocal approach focusing on the support of female scientists and at the same time having necessary organizational change in view (de Vries, 2011). Highlight projects between 2012 and 2019, as described by Kamm and Weber (2018), were the mentoring program via:mento_ocean by "The Future Ocean" (see Sect. 4.1), a targeted women's quota for filling positions, especially on the $\mathrm{PhD}$ and postdoc level by both alliances (see Sect. 4.2), and the code of conduct by the SFB 754 (see Sect. 4.3).

\section{1 via:mento_ocean - a mentoring program to support career entry and progression of female postdoctoral researchers}

Between 2013 and 2018 via:mento_ocean offered a combination of a one-on-one mentoring relationship, professional training courses and networking to female postdoctoral researchers from all fields of marine sciences. This mentoring program started as a joint project of "The Future Ocean", and the SFB 754 and its management was in the hands of the coordinator for gender measures. The program was designed as a branch of Kiel University's multidisciplinary program via:mento. In contrast to the existing program, however, this English-speaking program was open to female postdoctoral researchers working at all partner institutions involved in the cluster and the SFB 754, and it equally addressed the German and the international postdoc community of both research alliances. Over the course of the three program cycles carried out, 38 female scientists from various disciplines in all fields of marine sciences in Kiel with diverse national backgrounds took part.

The demand for a mentoring program like via:mento_ocean was seen both at GEOMAR and in marine sciences at Kiel University due to the existing underrepresentation of women at the professorship level and among permanent research staff relative to postdoc and fixed-term positions (see Sect. 2). Structured mentoring programs like via:mento_ocean (cf. Clem at al., 2014; Avallone et al., 2013) therefore follow several goals: (i) supporting career planning, (ii) empowering career advancement and (iii) strengthening networking among peers (de Vries, 2011: pp. 6,7). Getting individual guidance to strategically plan and follow an academic career is the primary idea of the one-on-one mentoring relationship. Each mentee was supported in finding an experienced female or male researcher from the same or a related field as a mentor. Mentors were preferably from outside Kiel to allow mentees to gain insights into a different working environment and to have an exchange without the interference of day-to-day work. In an introductory workshop, mentees had the chance to shape their individual priorities for the mentoring relationship as a basis for identifying suitable mentors. Workshops enabled the mentees to gain new skills and insights needed for successful career advancement across all disciplines such as a better understanding of appointment procedures and improved presentation techniques. Building a strong network among female peers through meetings within the mentee group was a valuable source of informal information and emotional support. These meetings were also used to increase knowledge on structures and processes in marine science in Kiel, e.g., regulations to get tenure.

The overall structure of via:mento_ocean was designed similarly to the mother program, which proved advantageous, especially in the planning and implementation phase. However, the frequency and content of networking events 
and workshops were adapted to the needs of mentees in marine sciences that included, for example, longer absences from Kiel due to scientific cruises or research stays abroad, trainers with experience in natural sciences, and an international research environment. Program-internal statistics show that via:mento_ocean was particularly attractive for participants not working or studying in Kiel before starting their postdoc, which was the case for roughly $65 \%$ of all mentees. Our assumption was that this explains why the program was well-received within the postdoc community of "The Future Ocean", whereas the female SFB 754 postdocs showed little interest. The vast majority of SFB 754 postdocs worked in Kiel before, either in a postdoc position or conducting a PhD thesis. Therefore, they already had good knowledge about working conditions, a close local network, and hence no need for additional networking and career support. However, even those SFB 754 female postdocs who were new to Kiel seemed not to acknowledge the added value. Our explanation is the very close peer network among doctoral candidates and postdocs as well as intensive exchange with senior scientists framed by the clearly defined common research topic the SFB 754 offered. Therefore, it was necessary to develop instruments suiting the SFB 754 community better, such as short workshops on gender awareness for the whole group of $\mathrm{PhD}$ candidates and postdocs as well as a training to improve self-confidence and learn self-defense techniques. The diverging needs within both research alliances were one reason for separating the joint position of the coordinator for gender measures for the SFB 754 and "The Future Ocean" after some years of practicing this model; via:mento_ocean was transferred to the cluster's sole organizational and financial responsibility after 4 years, too.

There is a continuing debate on how the effects of mentoring programs on career development can be measured (Dougherty and Dreher, 2007; de Vries, 2011). A majority of the participating mentees were able to start a fruitful and lasting exchange with an experienced member of their respective scientific communities in order to strengthen their career development. Nevertheless, we do not have fully reliable data sets on medium- and long-term career developments because the first program cycle ended 5 years ago and the last in 2019. So far, more than $70 \%$ of the former mentees are still working in science, $25 \%$ of them in permanent or tenure-track positions. In comparison, $80 \%$ of the 30 female postdocs working in the SFB 754 during the second and third funding phase (2012 to 2019) still have positions in science, $20 \%$ of them in permanent or tenure-track positions.

\subsection{Gender quotas in staff selection - a leadership tool for promoting female researchers}

In general, there is no uniform or even obligatory strategy for setting gender quotas in hiring processes in academia in Germany. Nevertheless, flexible quotas played an important role for collaborative research projects funded by the DFG.
Currently, the DFG expects the commitment of each CRC to a feasible but ambitious target quota for filling $\mathrm{PhD}$ and postdoc positions. Consequently, the SFB 754 set the aim of $50 \%$ women in $\mathrm{PhD}$ and postdoctoral positions in the second and third phase and met this aim in each phase. Clusters of Excellence have more flexibility in defining their actions to increase the number of female scientists involved in their community. Both the SFB 754 and "The Future Ocean" were in the challenging situation that they had only limited influence on the recruitment of female professors in Kiel. That is the reason why "The Future Ocean" decided to focus on gender parity in staff selection by setting a quota during hiring processes that was in its own hands. At the beginning of the cluster funding, 12 junior professors (equivalent to assistant professors either with or without tenure track in other academic systems) were hired. "The Future Ocean" targeted $50 \%$ women in these positions, and nine of them were offered tenure. All in all, five women started their junior professorship in Kiel, and four were tenured at Kiel University or GEOMAR. Another two women were offered positions, but they declined.

During the second funding phase from 2012 onwards the Cluster of Excellence focused on funding postdocs and developed a multistage recruitment process for postdocs. A postdoc project call was carried out three times, and the selection process and criteria were refined from call to call. The first call in 2012 relied on the fact that women would equally respond to the call without explicitly approaching them and on the inherent awareness of the cluster community and its ability to ensure gender equality at all steps in the application process without written goals. The share of less than $50 \%$ female postdocs hired, however, especially in 5-year positions for experienced postdoctoral researchers, prompted the leadership of the cluster to make adjustments when the next calls were initiated. Most importantly, the second and third calls in 2013 and 2017 included, amongst other quotas, the self-imposed goal of $50 \%$ women at all selection stages. The goal of $50 \%$ women comprised the application phase, the preselection of applicants to introduce their project idea to the cluster community at a symposium and the suggestion of a group of candidates that met the quota for the final anonymous decision by "The Future Ocean" executive board. Prior to the second call, an information leaflet on the gender quota was handed out to everyone involved. Hence, the thematic expert groups responsible for the preselection were highly aware of the gender quota when identifying suitable candidates for the symposium, and so was the committee that did the final ranking of applicants. The executive board decided on a number of funded projects without knowing who was ranked in which position, which supported a decision free of bias and personal interests. Experience from the first call in 2012 showed that realizing a high number of applications by women was a challenge. The gender quota was transparently communicated to give a clear signal to female postdocs to consider an application. Moreover, there was an 
attempt to positively influence the number of applications by women through active recruitment. All applicants were asked to name one of the cluster's senior scientists as a possible mentor after the symposium. The hope was that the increased number of - potential female mentors would encourage female scientists in their networks to apply, also by offering to become their formal mentors in the case that their application was successful. All in all, the formalization of the recruitment process led to high transparency and allowed for comparatively objective decisions. In the two selection processes with explicit gender quotas, the self-set aim was reached and therefore exceeded the gender ratio of the first postdoc call at all stages.

The coordinator for gender measures and Kiel University's equal-opportunity commissioner supported and monitored the processes at all steps. The outcome of the calls, in combination with the transparent and structured process, raised general awareness within the community on genderinclusive selection procedures. This was furthered through an accompanying expert talk, a workshop and a plenary discussion on gender-fair recruitment during a general annual cluster retreat that was attended by the majority of the members across all disciplines and career levels. Written material was distributed to the community afterwards.

\subsection{Code of conduct on basic values and rules for cooperation and communication - to create gender-fair working conditions}

After almost 10 years of joint research, the SFB 754 community decided to lay down its core values for conducting research. Their commitment to fair, respectful, nondiscriminatory, and inclusive communication and interaction, individualized career support, and transparent handling of scientific outputs was summed up and published in the code of conduct in 2017 (SFB 754, 2017). These values were grouped in six fields: (1) welcoming and family-friendly working conditions, (2) acknowledgment of the advantages of diversity, (3) a zero-tolerance attitude towards harassment or unjust treatment, (4) valuing an international and intercultural environment, (5) the commitment to structured career development support for nonpermanent research staff, and (6) the transparent publication of research output. The idea was not only to make the unwritten rules of the SFB 754 visible, but also to give an example for the wider marine sciences community in Kiel. The code of conduct was developed in an inclusive multistage process giving all SFB 754 members the opportunity to bring in their perception of the community's strengths in interaction and specifically supportive characteristics of collaboration. The general idea and possible aspects to be covered were developed by the coordinator of gender measures, the scientific coordinator, the scientific secretary and the speaker. After the SFB 754 community agreed upon the development of the code of conduct a participative iterative process started which gave all SFB 754 members the chance to actively discuss and refine the initial ideas orally and in written form in both plenary and small group settings.

In the code of conduct, gender is only indirectly addressed by encouraging diversity in research teams and respectful cooperation among members with different perspectives based on different genders, amongst others. However, the intention of the whole document is to support an open culture based on transparently communicated values that makes science as a workplace more attractive for all, especially for those not in the majority, such as women, from a more advanced qualification level onwards. The initiative to publish such a document proved successful because it intensified internal discussions about discrepancies in commitments and reality and helped SFB 754 members to call for improvements where necessary. Nevertheless, in conflict situations, the values of the SFB 754's code of conduct were not always completely compatible with the possibilities and legal options the institutions were able to offer. For example, procedures on what to do in case of sexual harassment - an aspect mentioned in the code of conduct - were not fully clarified and transparently communicated at GEOMAR or at Kiel University when the code of conduct was published. The code of conduct was well-perceived beyond the SFB 754 community and inspired other units to develop similar codes of behavior.

\section{Preconditions for successful measures to support gender equality in marine sciences}

In marine sciences in Kiel, manifold efforts to increase gender equality could be observed within the last decade, as exemplified by the three measures in Sect. 4. Different groups and single actors were involved, such as equalopportunity officers, program managers, heads of boards like the Women's Executive Board, and the speakers and wider leadership of research alliances. They made problems visible, implemented counter measures, and laid ground for changing formal regulations and structures. Looking at the successes and longer-lasting effects of these efforts is one of the aims of the project "Baltic Gender - Baltic Consortium on Promoting Gender Equality in Marine Research Organisations". Baltic Gender started in 2016 with eight institutions (with either their core focus on marine sciences or a unit dealing with marine sciences and technology) from five countries around the Baltic Sea. They cooperate to reduce gender inequalities in marine sciences and technology. Baltic Gender is funded for 4 years within the EU Horizon 2020 program as a support action aiming at improved gender equality through the implementation of gender equality plans. The project is led and coordinated by a team based at GEOMAR. Kiel University's equal-opportunity commissioner is leading a subproject focusing on structural change within academic institutions. The central question is how structures and processes at the partnering institutions affect women and men and how they could be organized in such a way to pro- 
mote gender equality in the institutions (Baltic Gender, 2020; Kamm and Weber, 2018). One idea of the project is to learn from each other. Within the subproject on structural change, criteria were developed to classify activities to increase gender equality in the Baltic Gender partner institutions as a set of best-practice measures to inspire the development of similar measures at other institutions. These criteria are the following.

1. Marine science specific. The inequality that shall be tackled is caused by specific conditions in the research field.

2. Need identified and goal defined. The established measures needs to have a clear-cut aim based on a specified need.

3. Long-term funding with a sustainable structure. A measure can only have a structural effect if financial and human resources are available as long as the need for its implementation is still there.

4. Monitoring. The attainment of the measure has to be reviewed in order to be able to adjust and refine it if necessary.

5. Well-known. There should be a great degree of awareness of the measure at the offering institution, especially within the target group, and dissemination of information is necessary.

6. Beyond legal requirements. A best-practice measure not only meets the legislative and institutional requirements, but also goes beyond legal minimum standards.

A best-practice measure has to meet at least four out of these six criteria. After applying them, 13 measures from six project partners could be identified to be presented in a best-practice catalog (Kamm and Weber, 2018) by using a multi-method approach combining the analysis of published material and group interviews with people involved in the activities as initiators, coordinators or participants. Amongst the selected best practices are the three measures presented in Sect. 4. They meet all criteria except secured long-term funding and the corresponding sustainable structure. Furthermore, the code of conduct was not monitored in a structured process as it was only in place for the last 2 years of the third and final SFB 754 funding period. The measures presented in Sect. 4 were linked to both the duration of "The Future Ocean" and the SFB 754 and were terminated when external funding ended. Nevertheless, they can still be inspiring examples for future efforts to improve gender equality in marine sciences in Kiel and elsewhere.

\section{Outlook: chances and limits for long-term effects by terminated project funding}

Academia is expected to take disadvantages for female researchers and inequalities between women and men in academic institutions seriously. Several players use their scope for action to enforce activities to improve gender equality on the level of research communities. In Germany, national and federal law, governance instruments like indicator-based funding and mandatory gender equality plans, and university policies give an inevitable mandate to promote gender equality. As shown based on the examples of the DFG and the Excellence Initiative in Sect. 4, external funding bodies can use their power to enforce activities to improve gender equality by shaping their funding regulations accordingly. This was also concluded by Engels et al. (2015) based on their research project that looked into efforts to improve gender equality within the Excellence Initiative during the first funding phase from 2006 onwards.

Developing a coherent gender equality concept and linking it to additional funds for its implementation is only a first step. To implement such a concept successfully, program leaders and other leading scientists have to advocate for the ideas developed during the application phase, and, at the same time, members of the community have to make active use of the offers. Whereas laws and university policies set a framework for action, research communities usually start with initiatives and actions directed at their members - either to support women in a disadvantageous setting or to increase awareness of existing disadvantages in order to initiate cultural change.

While now entering a phase in which the gender equality activities of the two research alliances solely rely on financial support by institutional funds, some drawbacks have to be acknowledged. There is no funding for additional staff to bundle gender equality activities for all the institutions involved in marine sciences in Kiel. Comprehensive measures like the cross-institutional mentoring program and innovative measures such as tailored training activities for the whole community ended, too. Hence, similar activities will be offered by the institutions to their members only, or explicit cooperation agreements have to be negotiated. Nevertheless, although around 10 years of active engagement for gender equality across institutions cannot alter institutions completely, the efforts left their marks. Some gender equality activities outlive the funding of gender measures and continue without additional financial support, but they require the engagement of current staff to continue. This is the case for the informal and partially coordinated networks that originated in past activities. For example, former mentees of via:mento_ocean formed a peer network of alumni which is currently supported (e.g., by updating contact details and informing members about events in Kiel) under the umbrella of the university-wide mentoring program via:mento. 
Based on the positive experiences of the marine sciences community, other institutional levels started to provide comparable measures, and they will profit from past expertise. Often the termination of external funds forces experienced staff to leave the institution, thus leading to a loss of expertise. Here staff members who were formerly in coordination positions supporting gender equality in both research alliances continued working at Kiel University and GEOMAR. They will now contribute their knowledge and contacts to activities that are planned in other research fields or on higher institutional levels. For example, Kiel University's gender consulting service builds upon the idea of the joint coordination position. This new unit was established at the Central Office for Gender Equality, Diversity and Family in 2019. The former coordinator for gender measures of "The Future Ocean" and the SFB 754 holds this position. This service supports externally funded collaborative research units in developing integrated gender equality concepts and how to implement them. It is especially valid for DFG-funded research alliances, which can use funds for activities to improve gender equality (see Sect. 4). As another example, Kiel-based CRCs from fields other than marine sciences plan to commit themselves to written statements similar to the code of conduct of the SFB 754. The mentoring experience in the international marine sciences community inspired the development of the new university-wide mentoring program via:mento_international starting at Kiel University in 2020 through financing by external project funds. The tested and well-proven staff selection procedures of "The Future Ocean" became a reference point beyond marine sciences and are adapted for new applications for external funding.

Despite most of the measures proving valuable in "The Future Ocean" and the SFB 754, they will not be continued within the marine sciences community. This shows that, unfortunately, around 10 years of active engagement for more gender equality in the research alliances did not lead to a fundamental change at the institutions. There is a chance, however, that they are anchored in the community and can thus be reinstalled if new funding can be acquired. Engaged actors in combination with external (financial) incentives still play an important role for action taken within most research communities and for the growing awareness of unequal opportunities as a problem they have to address. Nevertheless, the initiated positive developments can be used as a basis, reference point or inspiration to continue the efforts to improve gender equality beyond marine sciences. In our experience, to exert a positive influence on structures, the transfer of knowledge between actors engaged in gender equality work in large research alliances and other institutional units is required. A position based on the central level interconnecting the different units involved can effectively foster change processes. Furthermore, the integration of positively evaluated measures into institutional planning and a commitment to continue them under altered conditions are necessary. Funding agencies have a positive influence on the equal-opportunity efforts of research alliances. In order to secure positive long-term effects, they could use their power to demand more sustainable action by requesting universities to transfer successful activities into permanent structures and to ensure basic funding when projects end.

Data availability. The data that cannot be accessed through the referenced literature can be requested from the corresponding author.

Author contributions. RK worked as coordinator for gender measures in "The Future Ocean" and the SFB 754 between 2012 and 2017. She codesigned and implemented the gender equality concept of both projects as well as the mentoring program via:mento_ocean, conducted the best-practice collection within Baltic Gender, and coordinates the mentoring program via:mento.

CKS worked as the scientific coordinator of the SFB 754 between 2010 and 2019. From 2017 onwards, the coordination of gender measures has been part of her position. She designed and implemented the gender equality concept of the SFB 754 and was responsible for the overall coordination of the SFB 754 gender equality activities.

GB was the main liaison person between the coordinator for gender measures and the decision-making bodies within "The $\mathrm{Fu}$ ture Ocean". As coordinator of the Integrated Marine Postdoc Network between 2012 and 2019 she designed the postdoc project calls within "The Future Ocean".

Competing interests. The authors declare that they have no conflict of interest.

Special issue statement. This article is part of the special issue "Diversity and equality in the geosciences (EGU2019 EOS6.1 \& US4, AGU2018 ED41B, JpGU2019 U-02)". It is not associated with a conference.

Acknowledgements. The authors would like to thank all colleagues at Kiel University and GEOMAR involved in the activities and progress presented in this article. We also thank an anonymous reviewer and Sarah Cornell for their comments on the paper and the topical editor Katherine Richardson for her support.

Review statement. This paper was edited by Katherine Richardson and reviewed by Sarah Cornell and one anonymous referee.

\section{References}

Avallone, L. M., Hallar, A. G., Thiry, H., and Edwards, L. M.: Supporting the retention and advancement of women in the atmospheric sciences: What women are saying, B. Am. Meteorol. Soc., 94, 313-316, https://doi.org/10.1175/BAMS-D-1200078.1, 2013. 
Baltic Gender: Updated handbook of gender-sensitive indicators in the Baltic Gender project, available at: https:/www.baltic-gender.eu/documents/1199638/1385310/ MS23-Indicators.pdf/d192d45f-c351-45c7-a80a-36234f406730 (last access 19 May 2020), 2019.

Baltic Gender: Welcome to the Baltic Gender project. Baltic Consortium on Promoting Gender Equality in Marine Research Organisations, available at: https://www.baltic-gender.eu/, last access: 19 May 2020.

Clem, S. Legg, S., Lozier, S., and Mouw, C.: The impact of MPOWIR: A decade of investing in mentoring women in physical oceanography, Oceanography, 27, 39-48, https://doi.org/10.5670/oceanog.2014.113, 2014.

de Vries, J.: Mentoring for Change, Universities Australia Executive Women \& the LH Martin Institute for Higher Education Leadership and Management, Melbourne, Victoria, available at: http://jendevries.com/publications-full/2014/5/ 1/mentoring-for-change (last access: 21 July 2020), 2011.

DFG: Module Gender Equality Measures in Research Networks, DFG form 52.14 - 10/11, available at: https://www.dfg.de/ formulare/52_14/52_14_en.pdf (last access: 18 October 2019), 2011.

DFG: Clusters of Excellence Funding Line. Funding Criteria, DFG form ExStra 110 - 09/2016, available at: https://www.dfg. de/formulare/exstra110/exstra110_en.pdf (last access: 18 October 2019), 2016.

DFG: Guidelines for Safeguarding Good Research, Code of Conduct, available at: https://www.dfg.de/en/research_funding/ principles_dfg_funding/good_scientific_practice/index.html (last access: 21 July 2020), 2019.

Engels, A., Beaufaÿs, S., Kegen, N. V., and Zuber, S.: Bestenauswahl und Ungleichheit. Eine soziologische Studie zu Wissenschaftlerinnen und Wissenschaftlern in der Exzellenzinitiative, Campus, Frankfurt a.M./New York, 2015.

Dougherty, T. and Dreher, G. F.: Mentoring and career outcomes: Conceptual and methodological issues in an emerging literature, in: The handbook of mentoring at work. Theory, research, and practice, edited by: Ragins, B. R. and Kram, K. E., Sage Publishing, Thousand Oaks, 51-93, 2007.

Future Ocean: Cluster of Excellence "The Future Ocean". Understanding the ocean - sustaining our future, available at: https://www.futureocean.org/en/cluster/index.php, last access: 19 May 2020.

GEOMAR: Gleichstellungsplan 2015-2019, available at: https://www.geomar.de/fileadmin/content/zentrum/ Gleichstellung/GEOMAR_Gleichstellungsplan_2015-2019.pdf, (last access: 9 May 2020), 2015 (in German).
GEOMAR: GEOMAR Helmholtz Centre for Ocean Research Kiel, available at: https://www.geomar.de/en/centre/, last access: 19 May 2020a.

GEOMAR: Leadership Change at GEOMAR, Press release 11 May 2020, available at: https://www.geomar.de/en/ news/article/fuehrungswechsel-am-geomar, last access: 21 July 2020 b.

GEOMAR: Equivalent Opportunities for Women and Men, available at: https://www.geomar.de/en/gleichstellung, last access: 21 July 2020c.

GEOMAR WEB: Women's Executive Board, available at: https:// www.geomar.de/en/web, last access: 21 July 2020.

Kamm, R. and Weber, I.: Gender equality in marine sciences. Best practices on structural change, available at: http://oceanrep.geomar.de/44349/1/CAU_Baltic\%20Gender\% 20Broschu\%CC\%88re_2018_WEB-FINAL.pdf (last access: 18 October 2019), 2018.

Kiel University: Gender equality, available at: http: //www.gleichstellung.uni-kiel.de/en?set_language=en, last access: 19 May 2020.

KMS: About Kiel Marine Science (KMS), available at: https: //www.kms.uni-kiel.de/en/about-kiel-marine-science-kms?set_ language $=$ en, last access: 19 May 2020.

Netzwerk GenderConsulting: Netzwerk GenderConsulting in Forschungsverbünden, available at: https://www. netzwerk-gender-consulting.de/, last access: 12 May 2020.

Orcutt, B. N. and Cetinić, I.: Women in oceanography: Continuing challenges, Oceanography, 27, 5-13, https://doi.org/10.5670/oceanog.2014.106, 2014.

SFB 754: Code of Conduct, available at: https://www. sfb754.de/documents/18426/1060789/sfb_coc_web_1806. pdf/dd551171-6ef1-4ede-9288-fc8afd482ebd (last access 14 May 2020), 2017.

SFB 754: Sonderforschungsbereich 754. Climate - Biogeochemistry Interactions in the Tropical Ocean, available at: https:// www.sfb754.de/, last access: 11 May 2020.

Zuber, S.: Women in Cutting-edge Research - Gender Equality and the German Excellence Initiative, in: GenderChange in Academia: Re-mapping the Fields of Work, Knowledge, and Politics from a Gender Perspective, edited by: Riegraf, B., Aulenbacher, B., Kirsch-Auwärter, E., and Müller, U., VS-Verlag, Wiesbaden, 189-202, 2010. 